\title{
Hydrogen Peroxide Retention in Rime Ice
}

\author{
JefFerson R. SNider, Derek C. Montague, and Gabor Vali \\ Department of Atmospheric Science, University of Wyoming, Laramie
}

\begin{abstract}
The extent to which $\mathrm{H}_{2} \mathrm{O}_{2}$ dissolved in cloud droplets is trapped in rime ice affects the composition of precipitation and the rate of $\mathrm{H}_{2} \mathrm{O}_{2}$ removal from the atmosphere. Measurements were conducted in winter stratiform clouds at a remote mountain-top site in southeastern Wyoming, thus avoiding the difficulties of preparing laboratory clouds whose chemical and physical properties are similar to natural clouds. Quantities directly observed were $\mathrm{H}_{2} \mathrm{O}_{2}$ concentrations in cloud water collected as rime, air temperature, gaseous $\mathrm{H}_{2} \mathrm{O}_{2}, \mathrm{O}_{3}$, and $\mathrm{SO}_{2}$, and cloud liquid water concentration. Values of the retention coefficient, $\Gamma$, defined as the ratio of the $\mathrm{H}_{2} \mathrm{O}_{2}$ concentration in the melted rime sample divided by the equilibrium concentration in the supercooled droplets, were always less than unity $(\bar{\Gamma}=0.24 \pm 0.07)$. Correclions to account for the rapid reaction between dissolved $\mathrm{H}_{2} \mathrm{O}_{2}$ and sulfur(IV) increase the average value of the retention coefficient to only 0.30 . An observed correlation between $\Gamma$ and riming rate suggests that $\mathrm{H}_{2} \mathrm{O}_{2}$ is released to the gas phase during riming. These field measurements do not agree with laboratory determinations of $\Gamma$.
\end{abstract}

\section{INTRODUCTION}

The processes by which chemical species are incorporated into solid (ice) precipitation are complex. Previous investigations [Scott, 1981; Borys et al., 1983; Mitchell and Lamb, 1989] demonstrated that nonvolatile species (e.g., sulfate anion and the base cations) are transferred efficiently to ice during impaction of supercooled droplets, a process commonly referred to as riming. Studies of gas uptake by ice suggest that water soluble species such as hydrogen peroxide [Sigg and Neftel, 1988], nitric aciu [Huebert et al., 1983], and sulfur dioxide [Sommerfeld and Lamb, 1986; Valdez et al., 1989; Mitra et al., 1990] are readily incorporated into ice by adsorption and by trapping in the liquidlike film on ice surfaces growing by deposition (water vapor diffusion).

The extent to which dissolved gases, or potentially volatile dissolved species such as bisulfite, are retained during riming is still uncertain. Gas loss during riming is characterized by the retention coefficient, defined as the fraction (or percentage) of the aqueous phase saturated concentration of the component remaining in the rime ice. Laboratory measurements of the retention coefficient for sulfur dioxide $\left(\mathrm{SO}_{2}\right)$ in rime ice collected on a rotating collector within a laboratory chamber, vary between less than 10\% [Lamb and Blumenstein, 1987] and 60\% [Iribarne et al., 1990]. Carras and Macklin [1975] measured a similar range of retention coefficients for molecular oxygen $\left(\mathrm{O}_{2}\right)$ and concluded that retention varies with both droplet freezing rate and the temperature of the riming substrate.

In contrast to $\mathrm{SO}_{2}$ and $\mathrm{O}_{2}$, which are not sufficiently water soluble to be efficiently partitioned into droplets in liquid water clouds, the laboratory experiments of Iribarne and Pyshnov [1990] indicate that hydrogen peroxide $\left(\mathrm{H}_{2} \mathrm{O}_{2}\right)$ and other highly water soluble gases are retained in rime ice with unit efficiency.

In light of the diverse laboratory results for the $\mathrm{SO}_{2}$ retention coefficient, and because of the sensitivities of chemical processes in clouds to the retention of $\mathrm{SO}_{2}$ and $\mathrm{H}_{2} \mathrm{O}_{2}$ [Cho et al., 1989] there is a need for studies of gas retention during the riming process in natural clouds. In this paper comparisons are made between the concentrations of $\mathrm{H}_{2} \mathrm{O}_{2}$ in rime in winter stratiform clouds, and

Copyright 1992 by the American Geophysical Union.

Paper number 92JD00237.

0148-0227/92/92JD-00237\$05.00 predicted equilibrium concentrations. Our approach is to describe the techniques used to sample and quantify both gaseous and aqueous $\mathrm{H}_{2} \mathrm{O}_{2}$, to explain how the measurements can be used to calculate equilibrium aqueous concentrations, to analyze how the derived retention coefficients vary as a function of ambient conditions, and to propose a plausible explanation for the volatilization of dissolved $\mathrm{H}_{2} \mathrm{O}_{2}$ during rime formation.

\section{SAMPLING AND INSTRUMENT LOCATIONS}

Measurements were conducted at the Elk Mountain Observatory (EMO), located on an isolated peak in southeastern Wyoming. The peak rises $\sim 1 \mathrm{~km}$ above the surrounding plains. EMO (3.31 $\mathrm{km}$ above mean sea level $(\mathrm{msl})$ ) is located in a col below the western summit of Elk Mountain $(3.40 \mathrm{~km} \mathrm{msl})$. Rime ice samples were collected in both isolated cap clouds and larger orographic clouds enveloping the peak. Politovich and Vali [1983] have documented the microphysical characteristics of these clouds. Cloud tops are laminar and coincide with the top of a well-mixed boundary layer. Discontinuities in potential temperature and in humidity mark this interface in upwind soundings. The change in $\mathrm{H}_{2} \mathrm{O}_{2}$ mixing ratio across the interface at Elk Mountain is small (data to be published), in contrast with hill cap clouds which form in a more polluted environment [Gallagher et al., 1990].

The sampler and instrument locations at EMO can be seen in Figure 1. The instrumentation consists of monitors for $\mathrm{SO}_{2}, \mathrm{H}_{2} \mathrm{O}_{2}$, and $\mathrm{O}_{3}$, a cloud water content meter (the Commonweal th Scientific and Industrial Research Organization (CSIRO) probe, King et al. [1978]), meteorological instruments, and a data acquisition system. In addition to these measurements, all recorded at $1 \mathrm{~Hz}$ by the data acquisition system, event marks signifying the start and stop of cloud water collection intervals were also recorded. Rime samples were collected on the instrument platform.

Cloud water samples were collected as rime using the rotating dual-arm wire grid, referred to as the CWS [Snider, 1989]. The stainless steel grids (width $0.5 \mathrm{~mm}$ ) were exposed for 5 to $60 \mathrm{~min}$. The amount of water vapor deposited onto or sublimated from the rime deposit, and the deposit temperature, were calculated using the heat transfer equations of Ludlam [1951]. It was assumed that the deposit was a rotated cylinder of diameter equal to the interval-averaged width $(\sim 1.5 \mathrm{~mm})$ of the CWS samples. The vapor deposition to rime ice ratio is defined as the ice mass due to vapor deposition divided by the mass of liquid water frozen onto 




Fig. 1. Plan view drawing of the Elk Mountain Observatory showing the location of the cloud chemistry and meteorological sensors. The air sample manifold extends vertically above the walkway connecting the cold room and the instrument platform. The cloud water sampler (CWS), and sensors for the measurement of temperature $(\mathrm{T})$ and relative humidity $(\mathrm{RH})$ are located on the instrument platform. The CSIRO probe and a pitot tube are located in the wind tunnel.

the sampler. Negative values of this ratio indicate rime mass ioss by sublimation. Elapsed time between sample collection and sample melting was always less than 4 hours; samples were kept frozen in the meantime. To remove the rime from the collecting wires, electric power was applied to the grid, heating it just enough to start melting the rime where it contacted the wires. This allowed the rime to be pushed off the wires into a clean sample container.

Air samples were drawn through a downward-pointing inlet located 3-4 $\mathrm{m}$ above the winter snowpack. The airflow rate through the 73-mm ID aluminum manifold was $1070 \mathrm{~L} \mathrm{~min}^{-1}$ and corresponds to a velocity of $4.2 \mathrm{~m} \mathrm{~s}^{-1}$ and a Reynolds number of $2 \times 10^{+4}$. Precipitation-sized particles $(>100 \mu \mathrm{m})$ do not enter the inlet. Cloud droplets (mass-median radius $6.5 \mu \mathrm{m}$, see Rogers et al. [1983]; Stokes number $\sim 0.03$ ) are aspirated by the inlet and are then impacted on the ducting walls because the airflow is nonisoaxial and turbulent [Huebert et al., 1990]. The impacted droplets form a rime deposit in the first $0.1 \mathrm{~m}$ of the manifold.

The effect of the aluminum surfaces on trace gas concentrations within the manifold was examined by introducing $\mathrm{SO}_{2}$ and $\mathrm{H}_{2} \mathrm{O}_{2}$ from sources positioned upstream of the sample taps leading to the monitors. Tests were also conducted by spraying water into the 73-mm manifold inlet and by comparing gas mixing ratios detected in the aluminum manifold and in a $1.3-\mathrm{cm}$ ID Teflon manifold. All of the tests were conducted during clear air conditions. Measured $\mathrm{SO}_{2}$ and $\mathrm{H}_{2} \mathrm{O}_{2}$ mixing ratios varied by less than $15 \%$ during the tests, so it was assumed that trace gas adsorption was negligible.

\section{LWC AND TRACE GAS MEASUREMENI}

Both the CWS and the CSIRO probe were used to measure cloud liquid water content (LWC). The characteristics of the two instruments are compared in Table 1. The equations of Langmuir and Blodgett [1946] were applied to the average droplet spectrum of Elk Mountain clouds [Rogers et al., 1983] to estimate the droplet capture efficiencies. The difference between the capture efficiency of the CSIRO probe $(76 \%)$ and the average capture efficiency of the CWS $(78 \%)$ is less than the uncertainty associated with the LWC measurement. No correction for this difference is made in the data presented here.

The precision of the LWC measurement techniques was evaluated by comparing simultaneous measurements made with two CWS devices and by comparing the CWS with the CSIRO probe measurements averaged over the CWS sampling interval. An average error of $\pm 8 \%$, ascribed to variations in sample recovery and weighing, was deduced from the simultaneous CWS measurements. Comparison of LWC values from the CSIRO probe and the CWS revealed an average error of $\pm 0.03 \mathrm{~cm}^{3} \mathrm{~m}^{-3}$; this is comparable to the uncertainty associated with the calculated convective heat loss from the sensing wire of the CSIRO probe.

Since $\mathrm{H}_{2} \mathrm{O}_{2}$ is readily incorporated into ice growing by vapor deposition [Sigg and Neftel, 1988], samples for which the vapor deposition to rime mass ratio exceeded 0.1 were excluded from the analysis. The calculated vapor deposition to rime mass ratio is shown in Figure 2 for different temperature and LWC values. The 18 samples for which the ratio was greater than 0.1 were those at LWC $<0.07 \mathrm{~cm}^{3} \mathrm{~m}^{-3}$, and most were taken at temperatures colder than $-1^{\circ} \mathrm{C}$. For the 57 other samples the vapor deposition to rime mass ratio ranged between -0.05 and 0.08 . The temperature rise at the surface of the growing rime, due to latent heat release, was 0.4 to $1.6^{\circ} \mathrm{C}$. The largest deposit temperature was $-3.5^{\circ} \mathrm{C}$. Measured ambient temperatures were used to calculate the equilibrium concentrations of $\mathrm{H}_{2} \mathrm{O}_{2}$ and $\mathrm{S}(\mathrm{IV})$ in the collected samples.

TABLE 1. Cloud Water Collection and LWC Instrument Parameters

\begin{tabular}{lcc}
\hline & CWS & CSIRO \\
\hline Width, mm & $1.5^{*}$ & 1.8 \\
Velocity, $\mathrm{m} \mathrm{s}^{-1}$ & $13-24$ & 24 \\
Sampling rate, $\mathrm{m}^{3} \mathrm{~s}^{-1}$ & 0.11 & 0.002 \\
Capture efficiency, \% & $71-80$ & 76 \\
$50 \%$ size cut, $\mu \mathrm{m}$, radius & $4.0-2.8$ & 3.5 \\
\hline
\end{tabular}

Average width during a rime collection interval. 




Fig. 2. Ambient temperatures and cloud liquid water content for 75 rime samples collected at EMO between January and March of both 1988 and 1989. Contours illustrate the vapor deposition to rime mass ratio based on formulae of Ludlam [1951]. The 18 samples associated with vapor deposition to rime mass ratios greater than 0.1 (indicated by squares) were eliminated from the analysis of $\mathrm{H}_{2} \mathrm{O}_{2}$ retention coefficients. Samples associated with vapor deposition to rime mass ratios $<0.1$ but $>0.0$ are indicated by pluses. Samples associated with vapor deposition to rime mass ratios $<0.0$ are indicated by circles.

$\mathrm{SO}_{2}$ mixing ratios were measured using a flame photometric analyzer (Columbia Scientific Industries, model SA260). The analyzer was calibrated using a permeation oven calibrator and by dilution of bottled $\mathrm{SO}_{2}$ standards into the sample manifold. The analyzer has a detection limit of $0.1 \mathrm{ppbv}$ (parts per billion by volume; defined as twice the standard deviation of the instrumental baseline) when using a fuel source consisting of $\mathrm{H}_{2}$ spiked with 75 ppbv $\mathrm{SF}_{6}$. The time response $(1 / e)$ of the analyzer is $30 \mathrm{~s}$ for a step input of $0.5 \mathrm{ppbv} \mathrm{SO}_{2}$. Periodic zeroing was performed by passing the sampled air through denuders coated with lead peroxide and silver sulfate [Slanina et al., 1987].

A peroxide monitor based on the design of Lazrus et al. [1986] was used to assay $\mathrm{H}_{2} \mathrm{O}_{2}$ in air. The monitor has a time response of $15 \mathrm{~s}$ and a detection limit of 0.005 ppbv. In addition to $\mathrm{H}_{2} \mathrm{O}_{2}$, organohydroperoxides, which generally have smaller aqueous solubilities than $\mathrm{H}_{2} \mathrm{O}_{2}$, have been identified in air [Hellpointner and $G a ̈ b, 1989$ ] and were also detected by the instrument. The scavenging efficiency of organohydroperoxides in the monitor's stripping coil is assumed to be $100 \%$. The monitor was zeroed every 45 min using an oxidant trap containing $1 \%$ palladium on an alumina support.

Ozone was measured (during 1989 only) using a Thermoelectron Company (model 49) UV photometer. Zero and span checks were performed every $2-5$ days. Constant ambient pressure $(67 \mathrm{kPa})$ and temperature $\left(20^{\circ} \mathrm{C}\right)$ were used in the conversion of measured ozone concentrations to ambient mixing ratios.

\section{RIME SAMPLE PREPARATION AND ANALYSIS}

Aliquots of the cloud samples collected in 1989 were assayed for anions $\left(\mathrm{Cl}^{-}, \mathrm{NO}_{3}^{-}\right.$, and $\left.\mathrm{SO}_{4}^{2-}\right) \mathrm{pH}$, and mixed with the hydroperoxide reagent within $30 \mathrm{~min}$ of sample collection. In 1988 the hydroperoxide reagent was added within 4 hours of sample collection and the $p \mathrm{H}$ and anion analyses were conducted in Laramie, Wyoming, 2-10 days after sample collection. In both 1988 and 1989 , base cation $\left(\mathrm{Ca}^{2+}, \mathrm{Mg}^{2+}, \mathrm{Na}^{+}\right.$, and $\left.\mathrm{K}^{+}\right)$and ammonium concentrations were measured in Laramie by atomic absorption spectroscopy and ion chromatography 2-10 days after collection. The aliquots set aside for base cation and anion analysis were preserved by refrigeration and by the addition of chloroform to inhibit microbial degradation. For control, synthetic cloud water samples of known composition were processed together with the actual samples; based on these, the accuracy of ionic species concentrations is approximately $\pm 10 \%$.

The technique of Kok et al. [1986], in which aqueous hydroperoxides rapidly convert p-hydroxyphenylacetic acid to its highly fluorescent dimer in the presence of peroxidase, was employed in this work. The organohydroperoxide concentrations, inferred from catalase addition to a subset of cloud water samples collected at EMO, are always less than $10 \%$ of the $\mathrm{H}_{2} \mathrm{O}_{2}$ concentration [Snider, 1989], and therefore differences between the sum of all hydroperoxide concentrations and the $\mathrm{H}_{2} \mathrm{O}_{2}$ concentration $\left(\left[\mathrm{H}_{2} \mathrm{O}_{2}\right], \mathrm{M}\right)$ were ignored. Over half of the 1989 samples were divided into two aliquots: one was mixed with the hydroperoxide reagent within $20 \mathrm{~min}$ of collection, the other 2 - 5 hours later. The average difference in $\left[\mathrm{H}_{2} \mathrm{O}_{2}\right]$ for these two sets of aliquots $(-2 \pm 4 \%, n=16)$ is comparable to the precision of the technique. This result suggests that the 1988 measurements of $\left[\mathrm{H}_{2} \mathrm{O}_{2}\right]$ were not biased by the longer time between sample collection and addition of the hydroperoxide reagent.

\section{Calculation of THE RETENTION COEFFICIENT}

As in the laboratory riming experiments of Iribarne and Pyshnov [1990], the ratio of $\left[\mathrm{H}_{2} \mathrm{O}_{2}\right]$ divided by the equilibrium concentration in the supercooled droplets $\left(\left[\mathrm{H}_{2} \mathrm{O}_{2}\right]^{*}, \mathrm{M}\right)$ is defined as the retention coefficient $(\Gamma)$ :

$$
\Gamma=\left[\mathrm{H}_{2} \mathrm{O}_{2}\right] /\left[\mathrm{H}_{2} \mathrm{O}_{2}\right]^{*}
$$

In contrast to the work of Iribarne and Pyshnov [1990], who worked with prepared samples, we derived $\left[\mathrm{H}_{2} \mathrm{O}_{2}\right]^{*}$ from measurements of gaseous and aqueous $\mathrm{H}_{2} \mathrm{O}_{2}$, temperature, and liquid water content. The calculation rests on two assumptions. First, we assume that dissolved $\mathrm{H}_{2} \mathrm{O}_{2}$ and cloud interstitial $\mathrm{H}_{2} \mathrm{O}_{2}$ were in thermodynamic equilibrium prior to freezing. The equilibrium model of Brimblecombe and Dawson [1984] then describes the partitioning of $\mathrm{H}_{2} \mathrm{O}_{2}$ as

$$
\left[\mathrm{H}_{2} \mathrm{O}_{2}\right]^{*}=\mathrm{XP}_{\mathrm{emo}} /\left(\mathrm{LRTC}_{1}+\mathrm{C}_{2} / \mathrm{K}_{\mathrm{t}}\right)
$$

In (2), $\mathrm{X}$ is the potential mixing ratio of $\mathrm{H}_{2} \mathrm{O}_{2}$ defined as the mixing ratio that would result from evaporating all the cloud water and supplementing the gaseous $\mathrm{H}_{2} \mathrm{O}_{2}$ with that present in the liquid phase, $\mathrm{R}$ is the gas constant $\left(8.314 \mathrm{~J} \mathrm{~mol}^{-1} \mathrm{~K}^{-1}\right)$, the pressure at $\mathrm{Elk}$ Mountain $P_{\text {emo }}$ is $0.67 \times 10^{5} \mathrm{~Pa}, K_{h}$ is the Henry's Law coefficient for $\mathrm{H}_{2} \mathrm{O}_{2}\left(\mathrm{M} \mathrm{atm}^{-1}\right)$, $\mathrm{T}$ is the ambient temperature $(\mathrm{K}), \mathrm{C}_{1}$ and $\mathrm{C}_{2}$ are unit conversion factors equal to $10^{-3} \mathrm{~L} \mathrm{~cm}^{-3}$ and $1.013 \times 10^{5} \mathrm{~Pa}$ $\mathrm{atm}^{-1}$, respectively, and $\mathrm{L}$ is the liquid water content $\left(\mathrm{cm}^{3} \mathrm{~m}^{-3}\right)(\mathrm{X}$, $T$, and $L$ averaged over the sampling interval).

Second, we assume that in supercooled clouds, $\mathrm{X}$ is equal to the sum of the measured $\mathrm{H}_{2} \mathrm{O}_{2}$ mixing ratio ( $\chi_{\text {Incloud }}$ ), averaged over the sampling interval, and the concentration of $\mathrm{H}_{2} \mathrm{O}_{2}$ measured in the cloud water samples, also expressed as a gas-phase mixing ratio. This assumption is substantiated in the appendix.

Two conditions must be satisfied for the partition equilibrium model to be valid. First, the cloud base to EMO air parcel 
TABLE 2. Characteristic Times for Mass Transport, Reaction in Cloud Droplets, and Sample Preparation at Elk Mountain

\begin{tabular}{lll}
\hline & \multicolumn{2}{c}{ Characteristic Time, s } \\
\cline { 2 - 3 } & $\mathrm{H}_{2} \mathrm{O}_{2}$ & $\mathrm{SO}_{2}$ \\
\hline Diffusion in droplets ${ }^{*},+$ & $2 \times 10^{-3}$ & $2 \times 10^{-3}$ \\
Partition equilibrium ${ }^{*} ;$ & $2 \times 10^{+1}$ & $7 \times 10^{-1}$ \\
Reaction in droplets ${ }^{*} \S$ & $1 \times 10^{+3}$ & $7 \times 10^{+1}$ \\
Sample preparation (1989) & $2 \times 10^{+3}$ & $2 \times 10^{+3}$ \\
\hline
\end{tabular}

- Assuming average wintertime conditions at Elk Mountain:

$L W C=0.15 \mathrm{~cm}^{3} \mathrm{~m}^{-3}, \overline{\mathrm{r}}=6.5 \mu \mathrm{m}, \mathrm{T}=263 \mathrm{~K}$, potential mixing ratio of $\mathrm{SO}_{2}=0.6 \mathrm{ppbv}\left([\mathrm{S}(\mathrm{IV})]^{*}=3 \mu M\right.$ ), potential mixing ratio of

$\mathrm{H}_{2} \mathrm{O}_{2}=0.3$ ppbv $\left(\left[\mathrm{H}_{2} \mathrm{O}_{2}\right]^{*}=50 \mu M\right.$, and $\mathrm{pH}=4.5$.

$\dagger$ Characteristic time for diffusion in droplets given by $r^{2} / \pi^{2} \mathrm{D}$. Diffusion coefficients, $D$, for $S(I V)$ and $\mathrm{H}_{2} \mathrm{O}_{2}$ are assumed to be $2 \times 10^{-\circ}$ $\mathrm{m}^{2} \mathbf{s}^{-1}$.

¥ Calculated using equation (4) of Jacob [1985].

$\$$ Characteristic time for reaction in droplets is given by $\left(\mathrm{k}[\mathrm{S}(\mathrm{IV})]^{-1}\right.$ for $\mathrm{H}_{2} \mathrm{O}_{2}$, and by $\left(\mathrm{k}\left[\mathrm{H}_{2} \mathrm{O}_{2}\right]^{*}\right)^{-1}$ for $\mathrm{S}(\mathrm{IV})$. The pseudo second-order rate coefficient, $\mathbf{k}$, for $p \mathrm{H}=4.5$ is $2.8 \times 10^{+2} M^{-1} \mathrm{~s}^{-1}$ [Hoffmann and Calvert, 1985].

transport time must be larger than the time required for equilibration of gaseous and aqueous $\mathrm{H}_{2} \mathrm{O}_{2}$, referred to as the partition equilibrium time. A comparison of the transport time values at Elk Mountain, 400 × $230 \mathrm{~s}$ [Snider, 1990], with the partition equilibrium time in Table 2 , indicates that this condition is met. Although the gradient in $\mathrm{H}_{2} \mathrm{O}_{2}$ across the top boundary of the cloud is small and mixing rates at the top are also small (due to the stability and low turbulence level of the cloud), it is worth noting that equilibrium between gas and liquid phase $\mathrm{H}_{2} \mathrm{O}_{2}$ is expected even for entrained air. The characteristic time associated with cloud-top mixing in cap clouds, 10-100 s [Carruthers and Choularton, 1986], is probably longer than the partition equilibrium time. Thus for all three reasons the impacts of cloud-top entrainment are minimized.

Second, the rate of interphase $\mathrm{H}_{2} \mathrm{O}_{2}$ transport should be large in comparison to the rate of irreversible reactions which consume dissolved $\mathrm{H}_{2} \mathrm{O}_{2}$. In Elk Mountain clouds, the coreactant with the greatest potential for the removal of $\mathrm{H}_{2} \mathrm{O}_{2}$ from solution, is sulfur in the +4 oxidation state (S(IV)). Characteristic times for chemical reaction and mass transfer, as applied to average wintertime conditions at Elk Mountain, are summarized in Table 2. Considering the lifetime of the limiting reagent, S(IV), as well as the dissolved concentrations of $\mathrm{H}_{2} \mathrm{O}_{2}$ and $\mathrm{S}(\mathrm{IV})$, the characteristic time for diffusion within a droplet, and the time required for partition equilibrium, it is apparent that $\mathrm{H}_{2} \mathrm{O}_{2}$ is not mass transport limited in orographic clouds at Elk Mountain. This generalization does not appear to be true in more polluted environments, such as those studied by Barth et al. [1989]. The assumption of partition equilibrium is consistent with simultaneous measurements of gaseous and aqueous $\mathrm{H}_{2} \mathrm{O}_{2}$ in warm stratiform orographic clouds [Noone et al., 1991] and in tropical rain showers with precipitation rates of less than $1 \mathrm{~mm} \mathrm{~h}^{-1}$ [Jacob et al., 1990]. Because the time interval between sample collection and addition of the hydroperoxide reagent, referred to as the sample preparation time in Table 2, is larger than the lifetime of dissolved S(IV), a modified retention coefficient, $\Gamma_{1}$, is used to account for the reaction between $\mathrm{H}_{2} \mathrm{O}_{2}$ and $\mathrm{S}(\mathrm{IV})$. This correction is obtained by modifying (1) in the following manner:

$$
\Gamma_{1}=\left(\left[\mathrm{H}_{2} \mathrm{O}_{2}\right]+[\mathrm{S}(\mathrm{IV})]^{*}\right) /\left[\mathrm{H}_{2} \mathrm{O}_{2}\right]^{*}
$$

The second term in the numerator of (3) accounts for the depletion of dissolved $\mathrm{H}_{2} \mathrm{O}_{2}$ due to reaction with $\mathrm{S}(\mathrm{IV})$. The equilibrium concentration of S(IV), [S(IV)]", was derived from measured $\mathrm{SO}_{2}$ mixing ratios, $p \mathrm{H}$, LWC, T, and the equilibria recommended by Maahs [1982]. It is assumed that dissolved $\mathrm{SO}_{2}$, bisulfite and sulfite anion are the only S(IV) species in solution. Although recent theoretical studies demonstrate that $[\mathrm{S}(\mathrm{IV})]^{*}$ is less than the actual S(IV) concentration [Pandis and Seinfeld, 1991], this underestimate is compensated by the fact that we have assumed that the retention coefficient for $\mathrm{SO}_{2}$ is equal to unity when calculating [S(IV)] ${ }^{*}$.

Calculation of $\left[\mathrm{H}_{2} \mathrm{O}_{2}\right]^{*}$ and $[\mathrm{S}(\mathrm{IV})]^{*}$ requires an extrapolation of thermodynamic data to the temperature of the measurements at EMO. The laboratory data reported by Lind and Kok [1986] and Maahs [1982] are used to calculate $\mathrm{K}_{4}$ for $\mathrm{H}_{2} \mathrm{O}_{2}$ and the enhanced Henry's Law coefficient for $\mathrm{SO}_{2}$, respectively.

Average values of the measured parameters $\mathrm{X}, \mathrm{T}, p \mathrm{H}, \mathrm{LWC}, \mathrm{SO}_{2}$ mixing ratio, and the derived values of $\Gamma$ and $\Gamma_{1}$ for the set of 57 samples with a vapor deposition to rime mass ratio less than 0.1 , are given in Table $3 a$. The mean values and standard deviations of the retention coefficients are $\bar{\Gamma}=0.24 \pm 0.07$ and $\bar{\Gamma}_{1}=0.30_{t}$ 0.10 .

\section{$\mathrm{H}_{2} \mathrm{O}_{2}$ RETENTION MEASUREMENTS}

The hydrogen peroxide retention coefficients, $\Gamma$ and $\Gamma_{1}$, are plotted versus temperature in Figure $3 a$, and versus $p \mathrm{H}, \mathrm{SO}_{2}$ mixing ratio, and $\left[\mathrm{Mg}^{2+}\right]$ (chemical factors that are anticipated to influence the concentration of $\mathrm{H}_{2} \mathrm{O}_{2}$ in rime ice) in Figures $3 b-3 d$. Although more complex functional interdependencies may be justified, we have chosen to apply simple, best fit linear relationships to the data. As discussed below, the observed differences between the best fit lines in the top and bottom panels of the figures suggest conditions favorable for $\mathrm{H}_{2} \mathrm{O}_{2}$ loss via reaction with $S(I V)$ and possibly with transition metals prior to addition of the hydroperoxide reagent.

[S(IV)] values for most of the samples collected in clouds colder than $-8^{\circ} \mathrm{C}$ are comparable to $\left[\mathrm{H}_{2} \mathrm{O}_{2}\right]$, and therefore $\Gamma_{1}$ is significantly larger than $\Gamma$ at the lowest temperatures shown in Figure $3 a$. This reflects both a seasonal trend in $\mathrm{H}_{2} \mathrm{O}_{2}$ abundance at Elk Mountain [Snider, 1990], and the inverse relationship between $\mathrm{SO}_{2}$ solubility and sulfurous acid strength with temperature. As a consequence of the differences between $\Gamma_{1}$ and $\Gamma$ at low temperatures, the weak correlation between $\Gamma$ and $T$ $(r=-0.17, P=0.11)$ is transformed into a significant correlation between $\Gamma_{1}$ and $T(r=-0.50, P<0.01)$.

Derived values of $[\mathrm{S}(\mathrm{IV})]^{*}$ also increase with $\mathrm{pH}$ and with $\mathrm{SO}_{2}$ mixing ratio. In Figure $3 b$ the inverse relationship between $\Gamma$ and $p \mathrm{H}(r=-0.36, P<0.01)$ is commensurate with $\mathrm{H}_{2} \mathrm{O}_{2}$ depletion by reaction with $\mathrm{S}(\mathrm{IV})$ prior to addition of the hydroperoxide reagent. Indeed, correction of the retention coefficients for the effect of this reaction results in the sign of the correlation coefficient for the $\Gamma_{1}$ versus $p H$ curve $(r=+0.28, P=0.02)$ to be opposite to that for the $\Gamma$ versus $p H$ curve. Similar differences in the signs of the correlation coefficients are noted (Figure $3 c$ ) between the $\Gamma$ versus $\mathrm{SO}_{2}$ mixing ratio $(r=-0.02, P=0.43)$ and the $\Gamma_{1}$ versus $\mathrm{SO}_{2}$ mixing ratio $(r=0.18, P=0.10)$ curves.

In Figure $3 d$ the inverse relationship between $\Gamma$ and $\left[\mathrm{Mg}^{2+}\right]$ ( $r=-0.26, P=0.04$ ) suggests another mechanism for the loss of dissolved $\mathrm{H}_{2} \mathrm{O}_{2}$ during sample collection or prior to hydroperoxide reagent addition. $\left[\mathrm{Mg}^{2+}\right]$ is correlated with the concentrations of dissolved transition metals in cloud water, snow, and aerosol 
TABLE 3a. Cloud Chemistry Measurements Associated With $\mathrm{H}_{2} \mathrm{O}_{2}$ Retention Measurements, Vapor Deposition to Rime Mass Ratio $<0.1$

\begin{tabular}{cccccccc}
\hline & $T, \cdot \mathrm{C}$ & $\mathrm{pH}$ & $\mathrm{LWC}, \mathrm{cm}^{3} \mathrm{~m}^{-3}$ & $\mathrm{X}, \mathrm{ppbv}$ & $\mathrm{SO}_{2}, \mathrm{ppbv}$ & $\Gamma$ & $\Gamma_{1}$ \\
\hline$\overline{\mathbf{x}}$ & -8.0 & 4.4 & 0.17 & 0.46 & 0.64 & 0.24 & 0.30 \\
$\sigma$ & 2.6 & 0.5 & 0.08 & 0.29 & 0.40 & 0.07 & 0.10 \\
$n$ & 57 & 57 & 57 & 57 & 57 & 57 & 57 \\
$\max$ & -4.0 & 5.5 & 0.41 & 1.39 & 2.04 & 0.40 & 0.56 \\
$\min$ & -12.9 & 3.6 & 0.04 & 0.10 & 0.04 & 0.07 & 0.07 \\
\hline
\end{tabular}

samples collected at Elk Mountain [Snider, 1989]. Such species are known to catalyze the decomposition of aqueous $\mathrm{H}_{2} \mathrm{O}_{2}$ [Walling, 1975]. Therefore the inverse relationship between $\left[\mathrm{Mg}^{2+}\right]$ and $\Gamma$ could be indicative of reactions between dissolved $\mathrm{H}_{2} \mathrm{O}_{2}$ and transition metals. S(IV) may also play a role in these reactions by reducing $\mathrm{Fe}$ (III) to $\mathrm{Fe}(\mathrm{II})$, thereby initiating a chain reaction mechanism involving the hydroxyl and hydroperoxy radicals.

Differences between the best fit lines in the top and bottom panels of Figures $3 a-3 d$, can be ascribed to the reaction of $\mathrm{H}_{2} \mathrm{O}_{2}$ with S(IV), and possibly to additional reactions with transition metals. In Figures $4 a$ and $4 b$, and in Table $3 b$, a subset of $\Gamma$ values for samples with [S(IV)] $/\left[\mathrm{H}_{2} \mathrm{O}_{2}\right]^{*}$ ratios $<0.1$ and with $\left[\mathrm{Mg}^{2+}\right]<2.5 \mu M$ are selected, so that $\mathrm{H}_{2} \mathrm{O}_{2}$ volatilization during rime collection can be distinguished from chemical loss processes. Most of the riming events yielding data for this subset of retention coefficient values occurred at temperatures warmer than $-11^{\circ} \mathrm{C}$.

Figure $4 a$ illustrates a positive correlation between $\Gamma$ and the rate of rime collection on the CWS $(r=+0.49, P<0.01)$. Riming rate can be related to the droplet impaction time, $\tau_{\text {im }}$, defined as the average time required for an impacted droplet to be covered by another droplet:

$$
\tau_{\text {im }}=4 \rho w l r / 3 \alpha
$$

where $\alpha$ is the riming rate $\left(\mathrm{kg} \mathrm{s}^{-1}\right)$, w $\left(\sim 1.5 \times 10^{-3} \mathrm{~m}\right)$ is the interval-averaged width of the CWS, $1(2.2 \mathrm{~m})$ is the length of the wire grid, and the mass per unit projected impaction area of a droplet $(4 \mathrm{pr} / 3)$ is $\sim 10^{-2} \mathrm{~kg} \mathrm{~m}^{-2}$ for a mass-median droplet of 6.5 $\mu \mathrm{m}$ (Rogers et al., 1983). Values of $\tau_{\text {im }}$ lie in the range $1.2-19.0$ $s$ for the observed riming rates.

Figure $4 b$ shows plots of $\Gamma$ and $\Gamma_{1}$ versus $\tau_{1 \mathrm{~m}}$. The inverse correlation between $\Gamma$ and $\tau_{\text {im }}(r=-0.69, P<0.01)$ and the positive correlation between $\Gamma$ and $\alpha$ are consistent with the assumption that entrapment of $\mathrm{H}_{2} \mathrm{O}_{2}$ is enhanced at higher riming rates by an increase in the rate at which droplets are buried by subsequent collection events.

\section{DISCUSSION}

The values of the retention coefficients found in this study are substantially lower than those obtained in the laboratory experiments of Iribarne and Pyshnov [1990]. Iribarne and Pyshnov collected rime on an unventilated substrate, located at the bottom of a thermally stratified chamber. They used water droplets (mass-weighted radius $28 \mu \mathrm{m}, \mathrm{LWC} \sim 5 \mathrm{~cm}^{3} \mathrm{~m}^{-3}$ ) containing between $10^{-3}$ and $1 M \mathrm{H}_{2} \mathrm{O}_{2}$. In our experiments, the rime accumulated under strongly ventilated conditions, from smaller drop sizes and lower values of LWC. These conditions gave rise to much faster freezing rates of the droplets. In addition, it is plausible that the unventilated conditions of the laboratory experiments led to a local buildup of $\mathrm{H}_{2} \mathrm{O}_{2}$ near the rime surface, so that riming in fact took place in higher ambient concentrations than believed. Because of the lower solubility of $\mathrm{SO}_{2}$, in comparison to $\mathrm{H}_{2} \mathrm{O}_{2}$, this explanation of the difference between field and laboratory results is not inconsistent with the work of Iribarne et al. [1990] who demonstrated that the $\mathrm{SO}_{2}$ retention cefficient is invariant with the type of collection mechanism (i.e., unventilated droplet sedimentation versus ventilated impaction).

In discussing $\mathrm{SO}_{2}$ retention in rime ice, previous investigators [Lamb and Blumenstein, 1987; Iribarne et al., 1990] have considered three relevant time scales, namely, (1) the characteristic time $\left(\tau_{d}\right)$ associated with diffusion in a cloud droplet, (2) the characteristic time associated with the adiabatic freezing stage $\left(\tau_{\mathrm{fl}}\right)$, and (3) the characteristic time required for droplet freezing subsequent to the adiabatic stage $\tau_{\mathfrak{R}}$. The two freezing processes will be referred to as the "adiabatic" and "second" freezing stages.

Comparison of the relative values of $\tau_{\mathrm{im}}, \tau_{\mathrm{d}}, \tau_{\mathrm{fl}}$, and $\tau_{\mathrm{n} 2}$ gives an insight into the mechanism of volatile solute loss during the riming process. For a $6.5-\mu \mathrm{m}$ droplet at a temperature of $-10^{\circ} \mathrm{C}$, the characteristic times are ranked in the following manner: $\tau_{\mathrm{im}}(5 \mathrm{~s})$ $>\tau_{\mathrm{f} 2}\left(5 \times 10^{-3} \mathrm{~s}\right) \geq \tau_{\mathrm{d}}>\tau_{\mathrm{fl}}\left(\sim 10^{-4} \mathrm{~s}\right)$. Increases in the extent of adiabatic freezing at lower temperatures [Lamb and Blumenstein, 1987] and enhanced $\mathrm{SO}_{2}$ entrapment due to decreasing values of $\tau_{\mathfrak{L}}$ at lower temperatures [Iribarne et al., 1990] have been put forward to explain the inverse relationship between temperature and the $\mathrm{SO}_{2}$ retention coefficient.

Usually, it is assumed that gas loss ceases subsequent to the second freezing stage because solute diffusivities in ice are orders of magnitude smaller than liquid phase diffusivities. However, observations of solute diffusivities in ice [Bamaal and Slotfeldt-Ellingsen, 1983; Kopp et al., 1965] are 2-5 orders of magnitude larger than estimates based on the self diffusion of

TABLE 3b. Cloud Chemistry Measurements Associated With $\mathrm{H}_{2} \mathrm{O}_{2}$ Retention Measurements, Vapor Deposition to Rime Mass Ratio $\left.<0.1,[\mathrm{~S}(\mathrm{IV})]^{3} / \mathrm{H}_{2} \mathrm{O}_{2}\right]^{*}$ Ratios $<0.1$, and $\left[\mathrm{Mg}^{2+}\right]<2.5$

\begin{tabular}{cccccccc}
\hline & $T, \cdot \mathrm{C}$ & $\mathrm{pH}$ & $\mathrm{LWC}, \mathrm{cm}^{3} \mathrm{~m}^{-3}$ & $\mathrm{X}, \mathrm{ppbv}$ & $\mathrm{SO}_{2}, \mathrm{ppbv}$ & $\Gamma$ & $\Gamma_{1}$ \\
\hline$\overline{\mathbf{x}}$ & -6.9 & 4.5 & 0.19 & 0.59 & 0.44 & 0.24 & 0.26 \\
$\sigma$ & 2.3 & 0.4 & 0.08 & 0.30 & 0.26 & 0.06 & 0.07 \\
$n$ & 31 & 31 & 31 & 31 & 31 & 31 & 31 \\
$\max$ & -4.0 & 5.4 & 0.41 & 1.39 & 1.08 & 0.37 & 0.38 \\
$\min$ & -12.9 & 4.0 & 0.04 & 0.13 & 0.04 & 0.07 & 0.07 \\
\hline
\end{tabular}



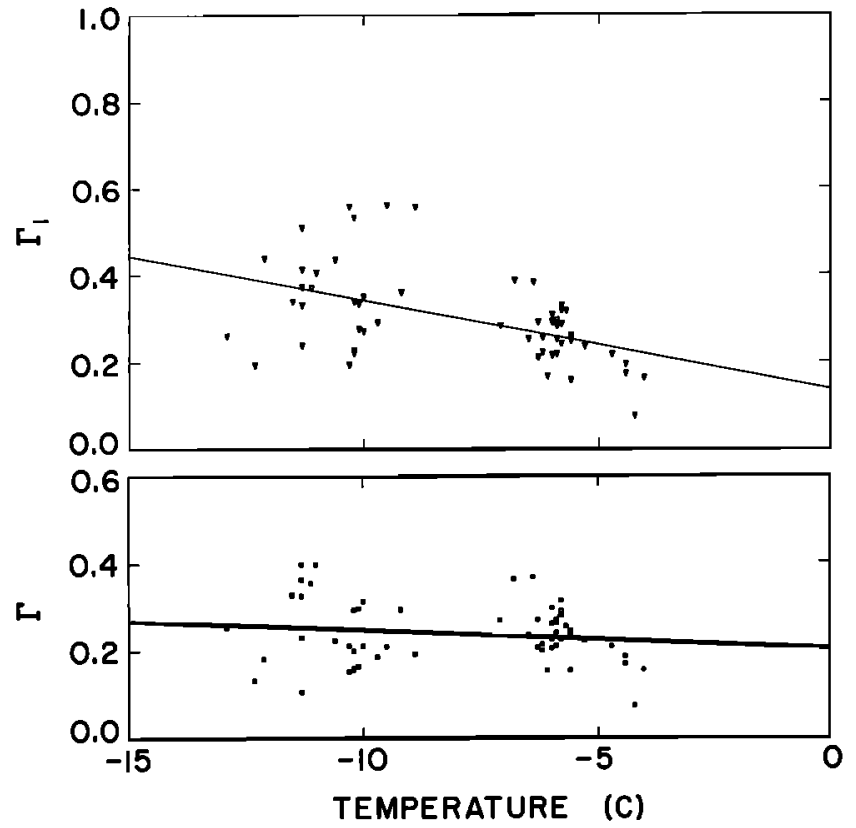

Fig. 3. (a) The variations of $\Gamma$ (bottom, $r=-0.17$ ) and $\Gamma_{1}$ (top, $r=-0.50$ ) with ambient temperature.

water molecules [Bari and Hallett, 1974]. Furthermore, rapid solute diffusion away from grain boundaries, due to increases in the local concentration gradient and the presence of liquid solutions, have been observed [Wolff et al., 1989]. These findings suggest that gas rejection subsequent to freezing and prior to the impaction of an overlying droplet might partially explain the low values of $\Gamma$ and $\Gamma_{1}$ observed in the Elk Mountain experiments. In addition, recent calculations [Baker et al., 1987] demonstrate that uniform and inward freezing of impacted water droplets on a ventilated surface, at temperatures warmer than $-20^{\circ} \mathrm{C}$, is expected

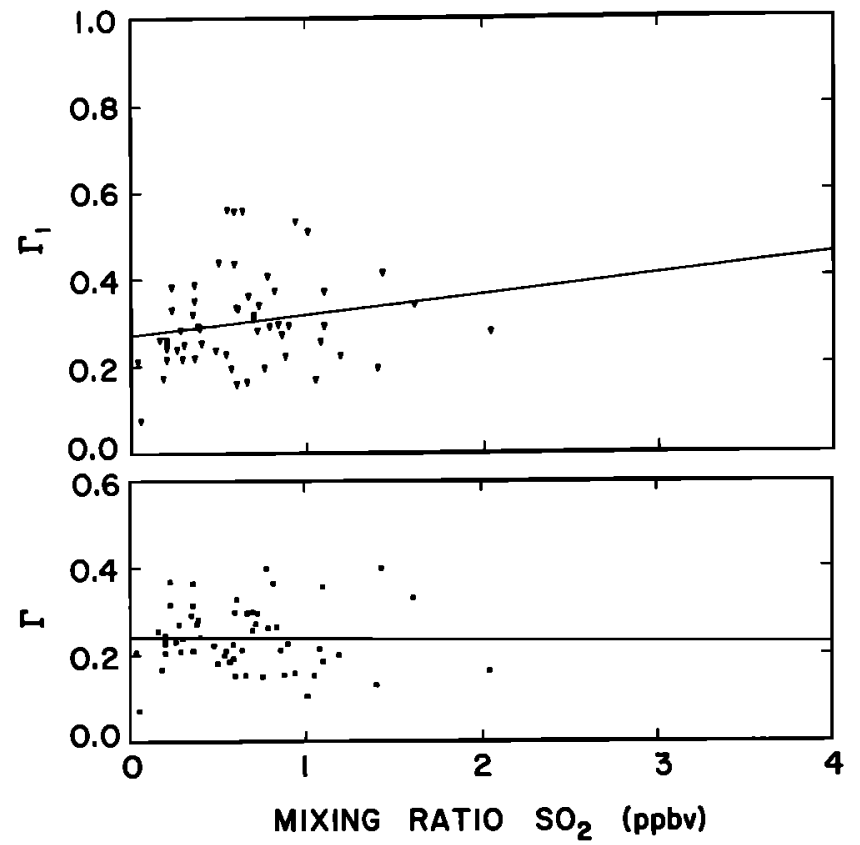

Fig. 3. (c) The variations of $\Gamma$ (bottom, $r=\mathbf{- 0 . 0 2}$ ) and $\Gamma_{1}$ (top, $r=0.18$ ) with $\mathrm{SO}_{2}$ mixing ratio.
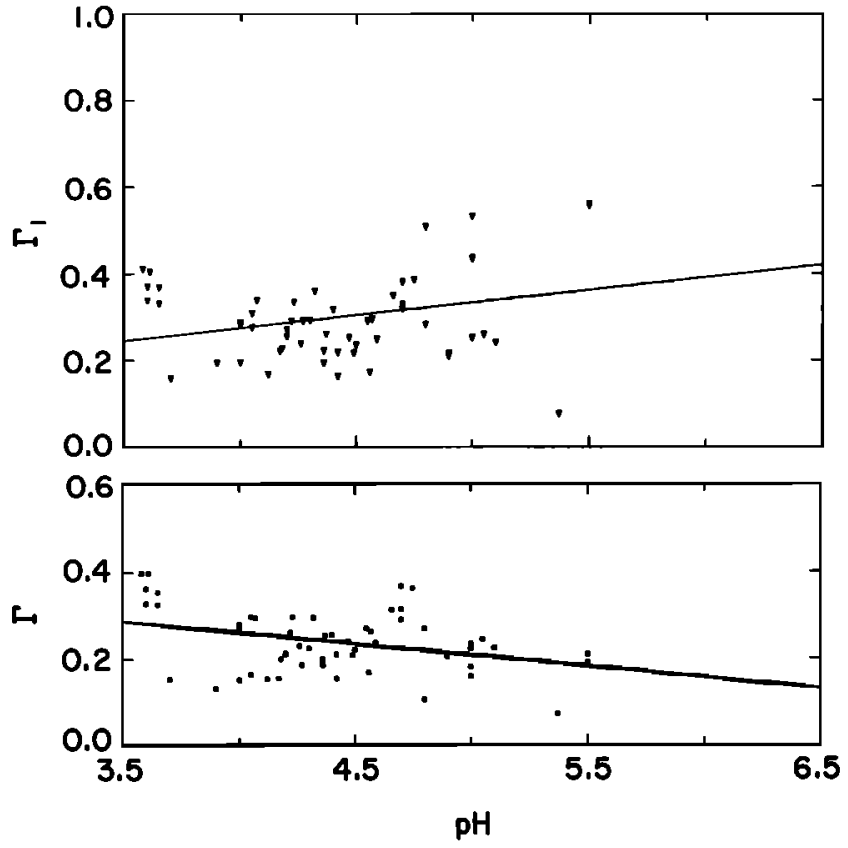

Fig. 3. (b) The variations of $\Gamma$ (bottom, $r=-0.36$ ) and $\Gamma_{1}$ (top, $r=0.28$ ) with $p H$.

to result in the formation of an ice shell, thereby enhancing the probability of droplet fracture [Bari and Hallett, 1974] or the formation of protuberances [Griggs and Choularton, 1983]. Such mechanical disruptions are also expected to lead to some loss of volatile solutes.

Because ice hydrometeors impact cloud droplets at lower velocities, are less ventilated than the samples collected on the CWS at Elk Mountain, and since cloud droplets are usually larger, the extent of $\mathrm{H}_{2} \mathrm{O}_{2}$ retention during riming on free-falling ice is likely to be different than the value found in this study. Lower



Fig. 3. (d) The variations of $\Gamma$ (bottom, $r=-0.26$ ) and $\Gamma_{1}$ (top, $r=0.14$ ) with $\left[\mathrm{Mg}^{2+}\right]$. 


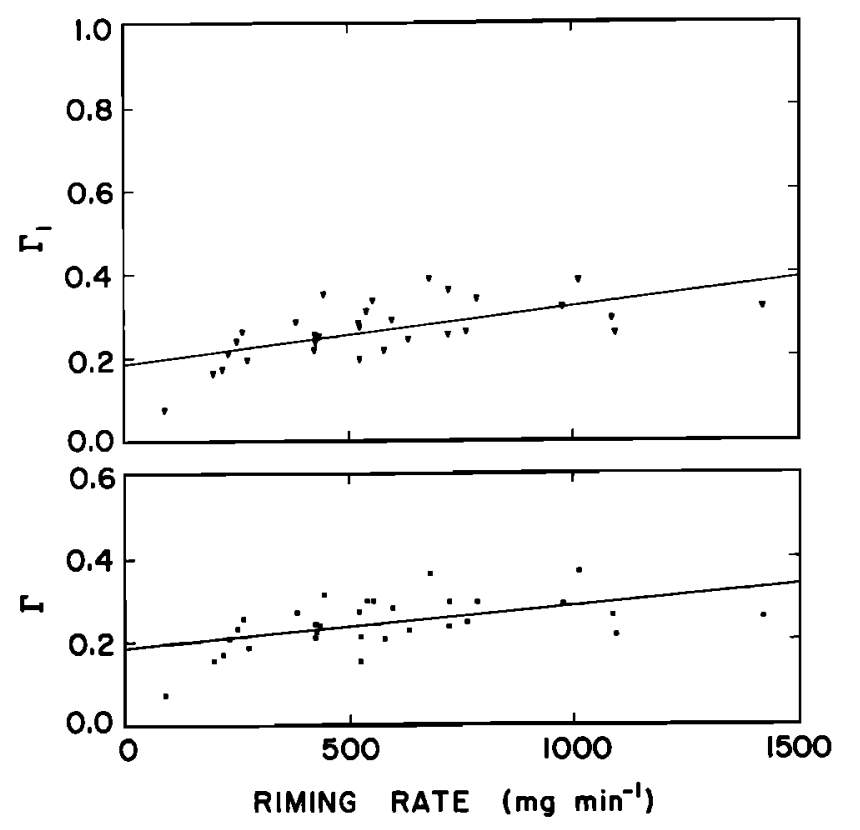

Fig. 4. (a) The variations of $\Gamma$ (bottom, $r=0.49$ ) and $\Gamma_{1}$ (top, $r=0.60$ ) with riming rate.

ventilation and lower probability of mechanical rupture should favor larger values of $\Gamma$. Conversely, larger values of $\tau_{\text {im }}$ will lead to smaller values of $\Gamma$. Only after these dependencies are established can extrapolation to different cloud conditions be formulated.

\section{CONCLUSIONS}

Measurements of gaseous and aqueous $\mathrm{H}_{2} \mathrm{O}_{2}, L W C$, and temperature in wintertime stratiform orographic clouds were used to calculate equilibrium $\mathrm{H}_{2} \mathrm{O}_{2}$ concentrations in supercooled cloud droplets. The equilibrium concentrations were compared with measurements of $\left[\mathrm{H}_{2} \mathrm{O}_{2}\right]$ in melted rime samples and yielded an
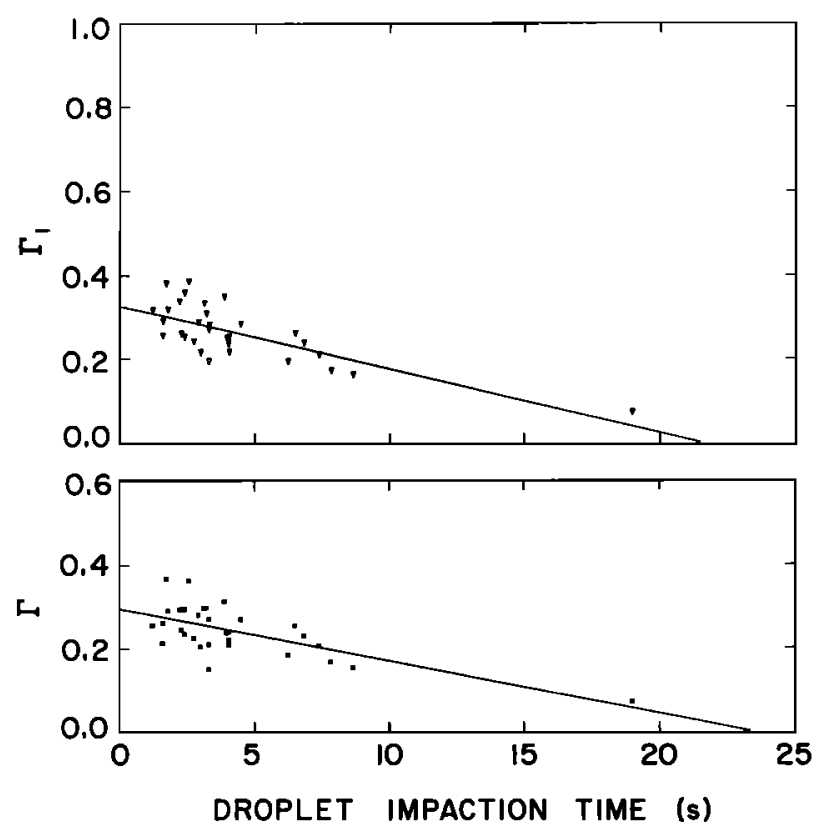

Fig. 4. (b) The variations of $\Gamma$ (bottom, $r=-0.69$ ) and $\Gamma_{1}$ (top, $r=-0.74$ ) with $\tau_{\text {m. }}$. average $\mathrm{H}_{2} \mathrm{O}_{2}$ retention coefficient, $\bar{\Gamma}$ of $0.24 \pm 0.07$. Sample preparation times were large relative to the lifetime of dissolved $\mathrm{S}(\mathrm{IV})$, hence a fraction of the dissolved $\mathrm{H}_{2} \mathrm{O}_{2}$ is consumed prior to hydroperoxide reagent addition. A modified retention coefficient was calculated to account for $\mathrm{H}_{2} \mathrm{O}_{2}$ loss via reaction with $\mathrm{S}(\mathrm{IV})$. The average value of the modified retention coefficient, $\bar{\Gamma}_{1}$, is 0.30 t 0.10. Because other chemical processes, in addition to reaction with S(IV), may also contribute to the removal of $\mathrm{H}_{2} \mathrm{O}_{2}$, and because there are uncertainties in the amount of dissolved S(IV) available for reaction with $\mathrm{H}_{2} \mathrm{O}_{2}$, it is difficult to estimate precisely the extent to which $\mathrm{H}_{2} \mathrm{O}_{2}$ is volatilized during riming in clouds. However, the relatively low value of $\bar{\Gamma}_{1}(0.26 \pm 0.07)$ for the 31 samples collected under conditions where inferred $S(I V)$ and trace metal concentrations are low provides a specific indication of significant $\mathrm{H}_{2} \mathrm{O}_{2}$ volatilization during droplet riming on a strongly ventilated collector.

A comparison of the time scales which are expected to govern gas entrapment in rime indicates that aqueous to gas phase transfer of dissolved $\mathrm{H}_{2} \mathrm{O}_{2}$ can occur through a solidified droplet if the $\mathrm{H}_{2} \mathrm{O}_{2}$ diffusivity in rime ice is greater than $5 \times 10^{-12} \mathrm{~m}^{2} \mathrm{~s}^{-1}$, or if $\mathrm{H}_{2} \mathrm{O}_{2}$ transfer is enhanced by segregation during freezing and by mechanical disruption of the freezing droplets.

The $\mathrm{H}_{2} \mathrm{O}_{2}$ retention measurements reported here were conducted in stratiform orographic clouds and therefore avoid possibly unrealistic conditions associated with laboratory studies such as those of Iribarne and Pyshnov [1990]. Uncertainty in the extent to which chemical reactions remove $\mathrm{H}_{2} \mathrm{O}_{2}$ prior to addition of the hydroperoxide reagent is the principal drawback of the field experiments.

Our observations of $\mathrm{H}_{2} \mathrm{O}_{2}$ loss via mass transfer imply that $\mathrm{H}_{2} \mathrm{O}_{2}$, like $\mathrm{SO}_{2}$ and the permanent gases, is released from hydrometeors growing by riming in clouds. The exact magnitude of the effect cannot be generalized to free-falling ice in the atmosphere since smaller droplets and larger collection velocities characterized the rime sample collection process at Elk Mountain. Release of $\mathrm{H}_{2} \mathrm{O}_{2}$ during riming can be expected to enhance interstitial $\mathrm{H}_{2} \mathrm{O}_{2}$ available for oxidation of $\mathrm{SO}_{2}$ in supercooled clouds, lower the concentrations of $\mathrm{H}_{2} \mathrm{O}_{2}$ in ice precipitation, and decrease the rate of $\mathrm{H}_{2} \mathrm{O}_{2}$ washout. It is clearly important that both field experiments using rime collectors which rotate more slowly than the CWS used in this work, and laboratory studies using ventilated collectors be conducted to resolve the current disparity between the field and laboratory determinations of the $\mathrm{H}_{2} \mathrm{O}_{2}$ retention coefficient.

\section{APPENDIX: ESTIMATION OF THE $\mathrm{H}_{2} \mathrm{O}_{2}$ POTENTIAL MIXING RATIO}

In this section comparisons are made between measurements of $\mathrm{H}_{2} \mathrm{O}_{2}$ during transitions from clear to cloudy conditions at EMO, and predictions, provided by the partition equilibrium theory, of $\mathrm{H}_{2} \mathrm{O}_{2}$ in the gaseous and aqueous phases. It is argued that values of $\mathrm{X}$, the $\mathrm{H}_{2} \mathrm{O}_{2}$ potential mixing ratio, required for the calculation of $\left[\mathrm{H}_{2} \mathrm{O}_{2}\right]$, can be approximated by the sum of two quantities measured in cloudy air: the gas phase $\mathrm{H}_{2} \mathrm{O}_{2}$ mixing ratio $\chi_{\text {incloud }}$ and the mixing ratio of cloud water dissolved $\mathrm{H}_{2} \mathrm{O}_{2}\left(\chi_{\text {ew }}\right)$.

The equilibrium mixing ratio of $\mathrm{H}_{2} \mathrm{O}_{2}$ dissolved in the cloud water $\left(\chi_{\mathrm{cw}}^{*}\right)$ divided by the equilibrium cloud interstitial $\mathrm{H}_{2} \mathrm{O}_{2}$ mixing ratio $\left(\dot{\chi}_{\mathrm{ei}}^{*}\right)$ is defined by the ratio $R(\mathrm{~T}, \mathrm{~L})$.

$$
R(T, \mathrm{~L})=\mathrm{K}_{\mathrm{h}} \mathrm{LRTC}_{1} / \mathrm{C}_{2}=\chi_{\mathrm{cw}}^{*} / \tilde{\chi}_{\mathrm{ci}}^{*}
$$

The symbols in (A1) are the same as utilized in (2). $\chi_{\mathrm{cow}}$ and $\chi_{\mathrm{ow}}^{*}$ 
TABLE A1. $\mathrm{H}_{2} \mathrm{O}_{2}$ Measurements During Clear-Air to In-Cloud Transitions

\begin{tabular}{|c|c|c|c|c|c|c|c|}
\hline \multirow[b]{2}{*}{ Date } & \multicolumn{4}{|c|}{$\mathrm{H}_{2} \mathrm{O}_{2}$ Measurement, ppbv } & \multirow[b]{2}{*}{$R(\mathrm{~T}, \mathrm{~L})$} & \multirow{2}{*}{$\begin{array}{c}\text { Model Predicted } \\
\text { Potential Mixing } \\
\text { Ratio, ppbv } \\
\text { X } \\
\end{array}$} & \multirow{2}{*}{$\begin{array}{c}\text { Observed Total In-Cloud } \\
\text { Mixing Ratio, ppbv } \\
\chi_{\text {ancload }}+\chi_{\text {ow }} \\
\end{array}$} \\
\hline & $\begin{array}{c}\text { Precloud, } \\
\chi_{\text {chouralr }}\end{array}$ & $\begin{array}{c}\text { In-Cloud, } \\
x_{\text {melond }}\end{array}$ & $\begin{array}{c}\text { In-Cloud, } \\
\chi_{\text {ew }}\end{array}$ & $\begin{array}{l}\text { Postcloud, } \\
\chi_{\text {eleardir }}\end{array}$ & & & \\
\hline \multicolumn{8}{|c|}{ Winter - Cold Clouds } \\
\hline 880309 & 0.28 & 0.26 & na & & 1.6 & 0.68 & $>0.26$ \\
\hline 880323 & 0.30 & 0.28 & 0.02 & & 1.1 & 0.61 & 0.30 \\
\hline 890105 & & 0.23 & na & 0.34 & 3.6 & 1.06 & $>0.23$ \\
\hline 890319 & 0.90 & 0.80 & 0.18 & & 5.4 & 5.12 & 0.98 \\
\hline 890320 & & 0.20 & na & 0.25 & 2.8 & 0.76 & $>0.20$ \\
\hline \multicolumn{8}{|c|}{ Summer - Warm Cloud } \\
\hline 890723 & 2.10 & 1.15 & na & & 0.5 & 1.72 & $>1.15$ \\
\hline
\end{tabular}

Abbreviation na $=$ not available

* Model predicted potential mixing ratio $=\chi_{\text {anclood }}(R(T, \mathrm{~L})+1)$.

$\dagger$ Observed total in-cloud mixing ratio $=\chi_{\text {inclosd }}+\chi_{\text {ow }}$.

are defined in terms of the measured $\left(\left[\mathrm{H}_{2} \mathrm{O}_{2}\right]\right)$ and equilibrium $\left(\left[\mathrm{H}_{2} \mathrm{O}_{2}\right]^{*}\right)$ concentrations in the liquid.

$$
\begin{aligned}
& \chi_{\text {cw }}=\left[\mathrm{H}_{2} \mathrm{O}_{2}\right] \mathrm{LRTC}_{1} / \mathrm{P}_{\text {emo }} \\
& \chi_{\text {ow }}^{*}=\left[\mathrm{H}_{2} \mathrm{O}_{2}\right]^{*}{ }^{*} \mathrm{LRTC} C_{1} / P_{\text {emo }}
\end{aligned}
$$

Table A1 documents changes in the $\mathrm{H}_{2} \mathrm{O}_{2}$ mixing ratio at the beginning and at the end of six wintertime and one summertime cloud episode. Values of $\chi_{\text {inctoud }}$ and $\chi_{\text {ow }}$ are summarized in the third and fourth columns. Clear-air measurements of $\mathrm{H}_{2} \mathrm{O}_{2}\left(\chi_{\text {clemirir }}\right)$ are summarized in the second and fifth columns. These values represent 5 to $10 \mathrm{~min}$ averages separated in time by observed transitions from in-cloud to cloud-free conditions.

In wintertime, measured values of $\chi_{\text {nclow }}$ are 7 to $32 \%$ lower than the corresponding $\chi_{\text {cleunir }}$ values. In summer, however, $\chi_{\text {incloud }}$ is $45 \%$ lower than $\chi_{\text {eleanir }}$ These findings suggest that $\mathrm{H}_{2} \mathrm{O}_{2}$ is released into the sampled airstream from cloud droplets that enter into and subsequently freeze within the sampling manifold. A model, based on partition equilibrium, and assuming negligible loss of $\mathrm{H}_{2} \mathrm{O}_{2}$ by reaction with $\mathrm{S}(\mathrm{IV})$, was used to evaluate this effect. In the model, complete retention of droplet-dissolved $\mathrm{H}_{2} \mathrm{O}_{2}$ is assumed, so that $\chi_{\text {Inctood }}$ is equal to $\chi_{\mathrm{ci}}^{*}$, and $\mathrm{X}=\chi_{\mathrm{ci}}^{*}+\chi_{\mathrm{ow}}^{*}$, can be evaluated as $\chi_{\text {inclood }}(R(T, L)+1)$.

For the wintertime experiments, a comparison of the model predicted mixing ratio (column 7 ) of $X$ to $\chi_{\text {cleannir }}$ indicates that the model overpredicts $X$ by greater than a factor of 2 . On the other hand, during the cold cloud events on 880323 and 890319 , for which both $\chi_{\text {incloud }}$ and $\chi_{\mathrm{cw}}$ data are available, the different relationship

$$
X=\chi_{\text {Inclowd }}+\chi_{\text {ow }}
$$
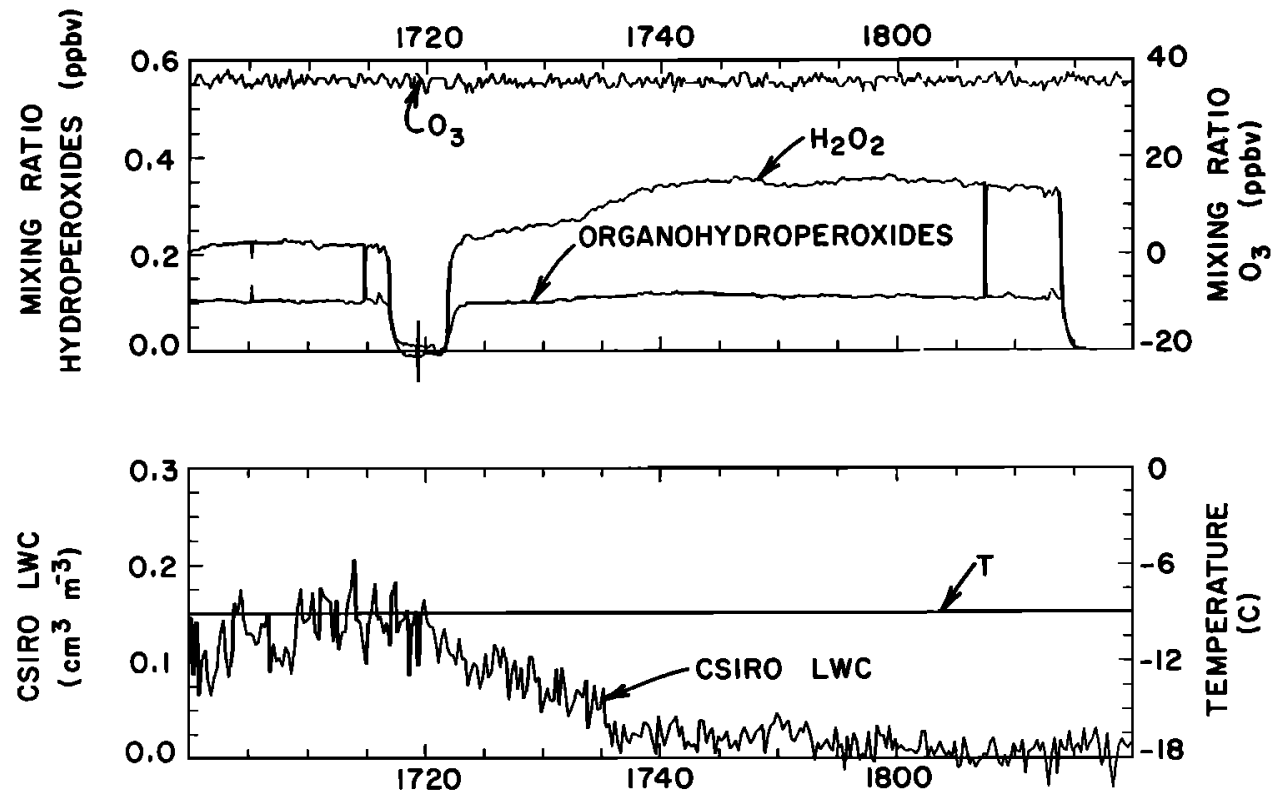

Fig. Al. (Top) $\mathrm{H}_{2} \mathrm{O}_{2}$, organohydroperoxides, and $\mathrm{O}_{3}$ mixing ratio, (bottom) CSIRO LWC and ambient temperature during the end of a cloud event on 890105. The measurements of $\mathrm{H}_{2} \mathrm{O}_{2}$ and the organohydroperoxides are zeroed during the 5-min intervals starting at 1717 MST and 1814 MST. 



Fig. A2. (Top) $\mathrm{H}_{2} \mathrm{O}_{2}$, organohydroperoxides, and $\mathrm{O}_{3}$ mixing ratio, (botlom) relative humidity and ambient temperature during the start of a cloud event on 890723. The measurements of $\mathrm{H}_{2} \mathrm{O}_{2}$ and the organohydroperoxides are zeroed during the 5-min intervals starting at $2111 \mathrm{MDT}$ and $2156 \mathrm{MDT}$.

gives $\mathrm{X}$ within $10 \%$ of $\chi_{\text {cleararr }}$ and with reasonable values of $\chi_{\mathrm{cw}}$ for the other cases the same is likely to be true. Equation A4, rather than the model discussed above, is therefore used for the evaluation of $\left[\mathrm{H}_{2} \mathrm{O}_{2}\right]^{*}$ in cold clouds. The summertime warm cloud event of 890723 is more consistent with the assumptions embodied in the model. The difference between wintertime and summertime observations is best illustrated by the following example.

Cloud chemistry $\left(\mathrm{H}_{2} \mathrm{O}_{2}, \mathrm{O}_{3}\right)$, cloud physics (LWC), and meteorological measurements ( $\mathrm{T}$, relative humidity) collected in association with the end of the cloud event on 890105 and with the beginning of a cloud event on 890723 are shown in Figures A1 and A2. From the in-cloud averages at $\sim 1710 \mathrm{MST}$ and the clear air measurements at $\sim 1750$ MST a 0.11 ppbv difference between $\chi_{\text {clearair }}$ and $\chi_{\text {incloud }}$ is indicated in Figure $\mathrm{A} 1$. Because $\mathrm{SO}_{2}$ mixing ratio values were below the detection limit of the flame photometric analyzer, the 0.11 ppbv difference in gaseous $\mathrm{H}_{2} \mathrm{O}_{2}$ is presumed to be due to the fact that some $\mathrm{H}_{2} \mathrm{O}_{2}$ is trapped in cloud droplets aspirated and subsequently rimed within the manifold inlet. However, the difference is 7.5 times smaller than the prediction of the model $\left(\chi_{\text {incloud }}(R(T, L)+1)-\chi_{\text {incloud }}=0.83 \mathrm{ppbv}\right)$, in agreement with our suggestion that most of the cloud water dissolved $\mathrm{H}_{2} \mathrm{O}_{2}$ is volatilized and sampled by the gas-phase hydroperoxide monitor. No variation in the organohydroperoxides or $\mathrm{O}_{3}$ are observed during the transition from cloudy to clear air. This observation is consistent with the lower solubility of these species and with the uniform properties of the sampled air mass.

The cloud studied on 890723 was associated with convection in the vicinity of Elk Mountain. Light rain was observed between 1930 and 2045 MDT. During the in-cloud and precipitation-free interval extending from 2110 to 2200 MDT the average LWC was $0.07 \mathrm{~cm}^{3} \mathrm{~m}^{-3}$. A mixture of rain and cloud was observed after 2200 MDT. The $\mathrm{SO}_{2}$ mixing ratio was initially $0.3 \mathrm{ppbv}$ and decreased to less than $0.1 \mathrm{ppbv}$ during the cloud interval. The decrease in the initial $\mathrm{H}_{2} \mathrm{O}_{2}$ mixing ratio (2.10 ppbv) starting at 2105 MDT is attributed to loss by reaction with $\mathrm{SO}_{2}$, and to the predicted amount of $\mathrm{H}_{2} \mathrm{O}_{2}\left(\chi_{\mathrm{ow}}^{*}=0.62\right)$ which is removed from the sampled air by cloud droplets, and remains in the water which impacts inside the inlet. (This assertion is consistent with the work of Noone et al. [1991] who removed cloud droplets by impaction prior to extracting sample air for the determination of $\chi_{c i}$ in a warm stratiform orographic cloud.) As $\chi_{\text {incloud }}=1.15 \mathrm{ppbv}$, almost all of the remaining $\mathrm{H}_{2} \mathrm{O}_{2}(2.10-0.62-0.30=1.18 \mathrm{ppbv})$ can be accounted for. In this case the model therefore provides a better prediction of $\mathrm{X}$ because there is no mechanism for volatilizing dissolved $\mathrm{H}_{2} \mathrm{O}_{2}$.

The case studies shown in Figures $\mathrm{A} 1$ and $\mathrm{A} 2$ support the hypothesis that $\mathrm{H}_{2} \mathrm{O}_{2}$ is released from cloud droplets during riming in supercooled clouds. Partial retention of $\mathrm{H}_{2} \mathrm{O}_{2}$ in rime near the inlet of the sample manifold and reaction with $\mathrm{SO}_{2}$ can explain the small but systematic difference between $\chi_{\text {clearair }}$ and $\chi_{\text {incloud }}$.

In the foregoing discussion it was assumed that the measured mixing ratios of $\mathrm{H}_{2} \mathrm{O}_{2}$ in clear air, prior to or subsequent to the cloud event, were representative of the mixing ratios entering the cloud. This assumption is supported by the fact that $\chi_{\text {aw }}+\chi_{\text {incloud }}$ is approximately equal to $\chi_{\text {clearair }}$ for the two samples where the data are available. The constancy of $\mathrm{O}_{3}$ and of the organohydroperoxides during changes from cloudy to clear air also support the assumption. The mixing ratios of $\mathrm{SO}_{2}$ were observed to change during the transitions; in-cloud values were lower by up to 0.4 ppbv. It thus appears that $\mathrm{SO}_{2}$ mixing ratios might be influenced by slight airflow changes in the vicinity of Elk Mountain. The contrast between $\mathrm{SO}_{2}$ and $\mathrm{H}_{2} \mathrm{O}_{2}$ is quite likely due to the influences of upwind sources of $\mathrm{SO}_{2}$.

Acknowledgments. Assistance provided by Greg Kok, Bill Bray, and the staff of the Department of Atmospheric Science is greatly appreciated. This work was supported by National Science Foundation grants ATM-8715294 and ATM-9012805.

\section{REFERENCES}

Baker, B., M. B. Baker, E. R. Jayaratne, J. Latham, and C. P. R. Saunders, The influence of diffusional growth rates on the charge transfer accompanying rebounding collisions between ice crystals and soft hailstones, Q. J. R. Meteorol. Soc., 113, 1193-1215, 1987.

Bari, S. A., and J. Hallett, Nucleation and growth of bubbles at an ice-water interface, J. Glaciol., 13, 489-520, 1974.

Barnaal, D., and D. Slotfeldt-Ellingsen, Pulsed nuclear magnetic 
resonance studies of doped ice Ih, J. Phys. Chem., 87, 4321-4325, 1983.

Barth, M. C., D. A. Hegg, and P. V. Hobbs, Measurements of atmospheric gas-phase hydrogen peroxide concentrations in winter on the east coast of the United States, Tellus, Ser. B, 41, 61-69, 1989.

Borys, R. D., P. J. Demott, E. E. Hindman, and D. Feng, The significance of snow crystal and mountain-surface riming to the removal of atmospheric trace constituents from cold clouds, in Precipitation Scavenging, Dry Deposition, and Resuspension, pp. 181189, Elsevier, New York, 1983.

Brimblecombe, P., and G. A. Dawson, Wet removal of highly soluble gases, J. Atmos. Chem., 2, 95-107, 1984.

Carras, J. N., and W. C. Macklin, Air bubbles in ice, Q. J. R. Meteorol. Soc., 101, 127-146, 1975.

Carruthers, D. J., and T. W. Choularton, The microstructure of hill cap clouds, Q. J. R. Meteorol. Soc., 112, 113-129, 1986.

Cho, H. R., M. Neiwiadomski, J. V. Iribarne, and O. Melo, A model of the effect of cumulus clouds on the redistribution and transformation of pollutants, J. Geophys. Res., 94, 12895-12910, 1989.

Gallagher, M. W., R. M. Downer, T. W. Choularton, M. J. Gay, I. Stromberg, C. S. Mill, M. Radojevic, B. J. Tyler, B. J. Bandy, S. A. Penkett, T. J. Davies, G. J. Dollard, and B. M. R. Jones, Case studies of the oxidation of sulfur dioxide in a hill cap cloud using ground and a ircraft based measurements, J. Geophys. Res., 95, 18517-18537, 1990.

Griggs, D. J., and T. W. Choularton, Freezing modes of riming droplets with application to ice splinter production, Q.J.R. Meteorol. Soc., 109, 243-253, 1983.

Hellpointner, E., and S. Gäb, Detection of methyl, hydroxymethyl and hydroxyethyl hydroperoxides in air and precipitation, Nature, 337, 631-634, 1989.

Hoffmann, M. R., and J. G. Calvert, Chemical transformation modules for Eulerian acid deposition models, volume II, The aqueous-phase chemistry, Rep. EPA/600/3-85/017, Environ. Prot. Agency, Research Triangle Park, N. C., 1985.

Huebert, B. J., F. C. Fehsenfeld, R. B. Norton, and D. L. Albritton, The scavenging of nitric acid vapor by snow, In Precipitation Scavenging, Dry Deposition and Resuspension, pp. 293-302, Elsevier, New York, 1983.

Huebert, B. J., G. Lee, and W. L. Warren, Airborne aerosol inlet passing efficiency measurement, J. Geophys. Res., 95, 16369-16381, 1990.

Iribarne, J. V., and T. Pyshnov, The effect of freezing on the composition of cloud droplets-I. Retention of $\mathrm{HCl}, \mathrm{HNO}_{3}, \mathrm{NH}_{3}$, and $\mathrm{H}_{2} \mathrm{O}_{2}$, Atmos. Environ., 24A, 383-387, 1990.

Iribarne, J. V., T. Pyshnov, and B. Naik, The effect of freezing on the composition of cloud droplets-II. Retention of S(IV), Atmos. Environ., 24A, 389-398, 1990.

Jacob, D. J., Comment on "The photochemistry of a remote stratiform cloud" by William L. Chameides, J. Geophys. Res., 90, 5864, 1985.

Jacob, P., T. M. Tavares, V. C. Rocha, and D. Klockow, Atmospheric $\mathrm{H}_{2} \mathrm{O}_{2}$ field measurements in a tropical environment: Bahia, Brazil, Atmos. Environ., 24A, 377-382, 1990.

King, W. D., D. A. Parkin, and R. J. Handsworth, A hot-wire liquid water device having fully calculable response characteristics, J. Appl. Meteorol., 17, 1809-1813, 1978.

Kok, G. L., K. Thompson, A. L. Lazrus, and S. E. McLaren, Derivatization technique for the determination of peroxides in precipitation, Anal. Chem., 58, 1192-1194, 1986.

Kopp, M., D. E. Barnaal, and I. J. Lowe, Measurement by NMR of the diffusion rate of HF in ice, J. Chem. Phys., 43, 2965-2971, 1965.

Lamb, D., and R. Blumenstein, Measurement of the entrapment of sulfur dioxide by rime ice, Atmos. Environ., 21, 1765-1772, 1987.

Langmuir, I., and K. B. Blodgett, Mathematical investigation of water-droplet trajectories, U.S. Air Force Tech. Rep. 5418, U.S. Amy Air Forces, 1946.

Lazrus, A. L., G. L. Kok, J. A. Lind, S. N. Gitlin, B. G. Heikes, and R. E. Shetter, Automated fluorometric method for hydrogen peroxide in air, Anal. Chem., 58, 594-597, 1986.

Lind, J. A., and G. L. Kok, Henry's law determination for aqueous solutions of hydrogen peroxide, methylhydrogen peroxide, and peroxyacetic acid, J. Geophys. Res., 91, 7889-7895, 1986.

Ludlam, F. H., The heat economy of a rimed cylinder, $Q . J . R$. Meteorol. Soc., 77, 663-666, 1951.

Maahs, H. G., Sulfur dioxide/water equilibria between $0^{\circ}$ and $50^{\circ} \mathrm{C}$. An examination of data at low concentrations, in Heterogeneous Atmospheric Chemistry, Geophys. Monogr. Ser., vol. 26, edited by D. R. Schryer, pp. 187-195, Washington, D. C., 1982.

Mitchell, D. L., and D. Lamb, Influence of riming on the chemical composition of snow in wintertime orographic storms, J. Geophys. Res., 94, 14831-14840, 1989.

Mitra, S. K., S. Barth, and H. R. Pruppacher, A laboratory study on the scavenging of $\mathrm{SO}_{2}$ by snow crystals, Atmos. Environ., 24A, 2307-2312, 1990.

Noone, K. J., J. A. Ogren, K. B. Noone, A. Hallberg, S. Fuzzi, and J. A. Lind, Measurements of the partitioning of hydrogen peroxide in a stratiform cloud, Tellus, Ser. B, 43, 280-290, 1991.

Pandis, S. N., and J. H. Seinfeld, Should bulk cloudwater or fogwater samples obey Henry's law?, J. Geophys. Res., 96, 10791-10798, 1991.

Politovich, M. K., and G. Vali, Observations of liquid water in orographic clouds over Elk Mountain, J. Atmos. Sci., 40, 1300-1312, 1983.

Rogers, D. C., D. Baumgardner and G. Vali, Determination of supercooled liquid water content by measuring rime rate, J. Climate and Appl. Meteor., 22, 153-162, 1983.

Scott, B. C., Sulfate washout ratios in winter storms, J. Appl. Meteor, 20, 619-625, 1981.

Sigg, A., and A. Neftel, Seasonal variations in hydrogen peroxide in polar ice cores, Ann. Glaciol., 10, 157-162, 1988.

Slanina, J., M. P. Keuken, and C. A. M. Schoonebeek, Determination of sulfur dioxide in ambient air by a computer-controlled thermodenuder system, Anal. Chem., 59, 2764-2766, 1987.

Snider, J. R., Measurement of sulfur dioxide reaction rates in wintertime orographic clouds, Ph.D. dissertation, 341 pp., Univ. of Wyo., Laramie, 1989.

Snider, J. R., Measurement of sulfur dioxide oxidation rates in wintertime orographic clouds, in Preprint Volume of the 1990 Conference on Cloud Physics, pp. 540-545, American Meteorological Society, Boston, Mass., 1990.

Sommerfeld, R. A., and D. Lamb, Preliminary measurements of $\mathrm{SO}_{2}$ absorbed on ice, Geophys. Res. Lett., 13, 349-351, 1986. Valdez, M. P., G. A. Dawson, and R. C. Bales, Sulfur dioxide incorporation into ice depositing from the vapor, J. Geophys. Res., 94, 1095-1104, 1989.

Walling, C., Fenton's reagent revisiled, Acc. Chem. Res., 8, 125-131, 1975.

Wolff, E. W., R. Mulvaney, and K. Oates, Diffusion and location of hydrochloric acid in ice: Implications for polar stratospheric clouds and ozone depletion, Geophys. Res. Lett., 16, 487-490, 1989.

D. C. Montague, J. R. Snider, and G. Vali, Department of Atmospheric Science, University of Wyoming, Laramie, WY 82071.

(Received April 26, 1991; revised January 28, 1992; accepled January 28, 1992.) 